\title{
Efficient Methane Production from Beer Wastewater in a Membraneless Microbial Electrolysis Cell with a Stacked Cathode: The Effect of the Cathode/Anode Ratio on Bioenergy Recovery
}

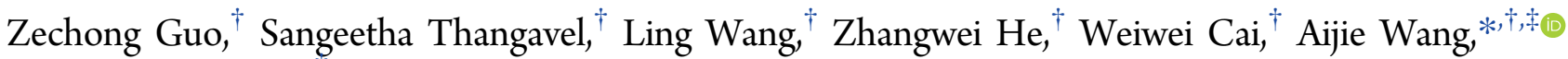 \\ and Wenzong Liu*, \\ ${ }^{\dagger}$ State Key Laboratory of Urban Water Resource and Environment (SKLUWRE), Harbin Institute of Technology (HIT), Harbin, \\ Heilongjiang 150001, People's Republic of China \\ ${ }^{\ddagger}$ Key Laboratory of Environmental Biotechnology, Research Center for Eco-Environmental Sciences, Chinese Academy of Sciences, \\ Beijing 100085, People's Republic of China
}

ABSTRACT: A methane-producing microbial electrolysis cell (MEC) is a promising energy-recovery technology, yet its performance is generally inhibited by the insufficient cathode/anode ratio. In this study, a novel stacked stainless-steel-mesh cathode was designed to investigate the effect of the cathode/anode ratio on methane production in semi-continuous MECs. Overall, energy recovery was significantly enhanced by increasing the cathode/anode ratio. The methane production rate in $\mathrm{R} 3$ (cathode/anode ratio of $4 \mathrm{~cm}^{2} / \mathrm{cm}^{3}$ ) reached $0.14 \mathrm{~m}^{3} \mathrm{~m}^{-3}$ day ${ }^{-1}$ with an applied voltage of $0.9 \mathrm{~V}$, which increased by $56-180 \%$ compared to the methane production rates in $\mathrm{R} 2\left(2.5 \mathrm{~cm}^{2} / \mathrm{cm}^{3}\right)$ and $\mathrm{R} 1\left(1 \mathrm{~cm}^{2} / \mathrm{cm}^{3}\right)$. The overall energy efficiency in R3 was 66-94\% higher than the overall energy efficiencies in R2 and R1. The cathode area was sufficient for obtaining and maintaining a maximum current when the cathode/anode ratio was higher than $2.5 \mathrm{~cm}^{2} / \mathrm{cm}^{3}$. According to electron balance analysis, when the cathode/anode ratio was less than $2.5 \mathrm{~cm}^{2} / \mathrm{cm}^{3}$, the methane production enhancement was mainly attributed to the promotion of bioelectrochemical performance, while the sole biomass contribution was enhanced and led to further improvement in overall methane production when the ratio was above $2.5 \mathrm{~cm}^{2} / \mathrm{cm}^{3}$. In general, increasing the cathode/anode ratio of the staked-style cathode would be an effective strategy to improve the methane production in the membraneless MECs.

\section{INTRODUCTION}

A microbial electrolysis cell (MEC) is a promising technology for recovering various valuable products from organic wastes. ${ }^{1,2}$ Methane was considered as an unwanted byproduct in hydrogen-producing MECs for a time ${ }^{3}$ but now become a research hotspot as a result of its bright prospects of commercial application. ${ }^{4,5}$ Electrochemical methanogenesis is more controllable and stable compared to conventional anaerobic methods. Lots of studies have confirmed the superiority of MECs or anaerobic digestion-microbial electrolysis cell (AD-MEC) coupling systems in recovering methane. $^{6-9}$

Despite some successful attempts, the methane-producing efficiency of MEC still needs to be further enhanced in view of scaling up and potential application. Some factors have been proven to have significant influences on the efficiency of the bioelectrochemical system (BES), including the reactor configuration, ${ }^{10}$ electrode material, ${ }^{7}$ properties of the electrode surface, ${ }^{11,12}$ size of electrodes, ${ }^{13,14}$ and influent characteristics (e.g., ammonia and $\mathrm{pH}) .{ }^{15-17}$ Considering the electrode size, the previous studies mainly emphasized the importance of enlarging the anode size for good electrochemical efficiency. However, the effect of the cathode area and the dimensional ratio between the cathode and the anode on total efficiency has seldom been investigated. The issue is worth investigating for promoting the overall energy efficiency and rationally distributing the reactor space.
Electron balance analysis (EBA) is an efficient tool for deeply understanding the electron transfer and utilization in a bioelectrochemical system. In previous works, EBA had been established in BESs for the anode-respiring process and pointed out that anode function was restricted by substrates. ${ }^{18}$ However, evaluating the effect of the electrode ratio in methane-producing MEC by EBA has not been performed in previous literature.

In this study, a novel stacked stainless-steel-mesh cathode with a high surface area was designed and the effect of the cathode/anode ratio (the ratio of cathode surface area/anode volume) on methane production was investigated in MECs with a constant anode size but different cathode area. The performances of chemical oxygen demand (COD) removal and methane production were analyzed under different applied voltage conditions. EBA was used to disclose the electrochemical and biological contributions in MECs with different cathode/anode ratios.

\section{METHODOLOGY}

2.1. Configuration of MEC with a Stacked Cathode. Three glass cylinder single-chamber MEC reactors (R1, R2, and R3) were conducted in this study. Each reactor had a working volume of $700 \mathrm{~mL}$ and a headspace of $100 \mathrm{~mL}$ (as seen in Figure 1). The anodes were made of identical graphite fiber brushes with a spatial volume of 78.5

Received: September 15, 2016

Revised: December 6, 2016

Published: December 12, 2016 


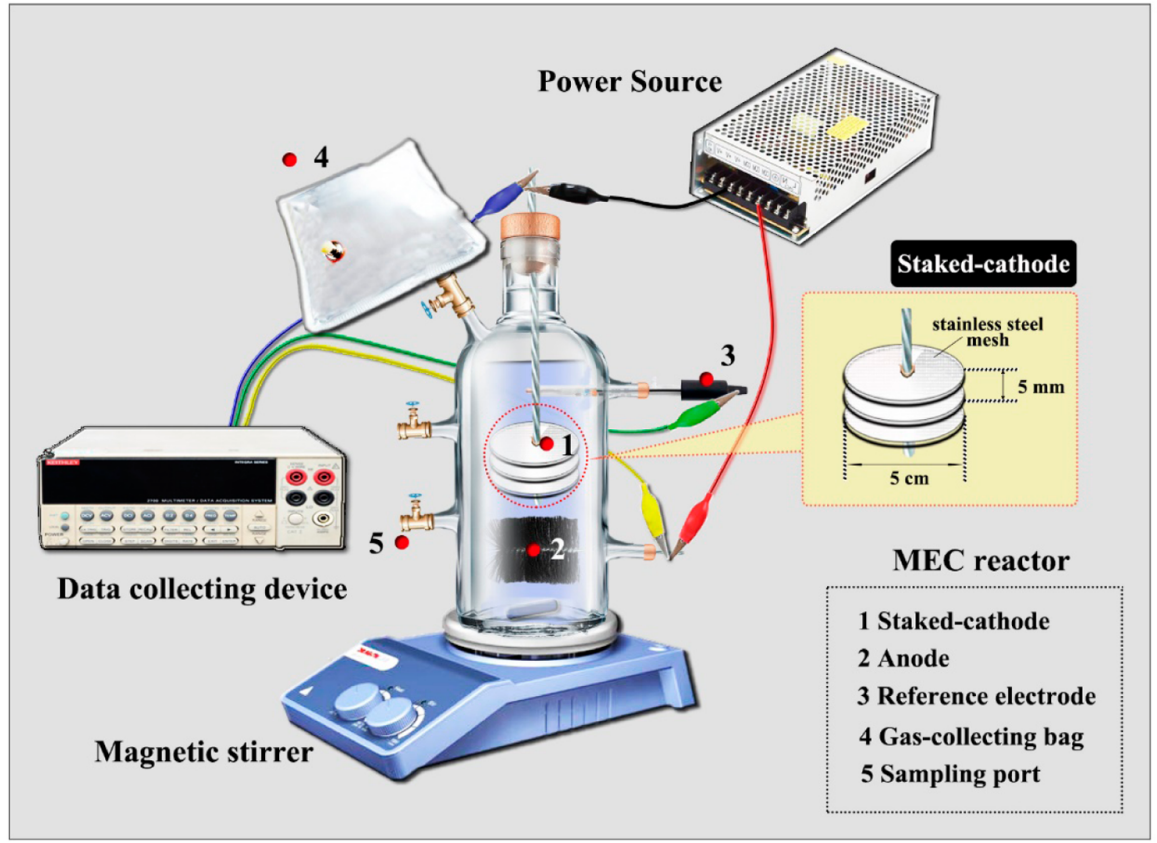

Figure 1. Scheme of the methane-producing MEC configuration.

$\mathrm{cm}^{3}$ ( $5 \mathrm{~cm}$ in diameter and $4 \mathrm{~cm}$ in length). The stacked cathodes were constructed of different layers of circular stainless-steel mesh (40 mesh and $5 \mathrm{~cm}$ in diameter) and installed in series by titanium wires with 5 $\mathrm{mm}$ interspace. There were two layers for R1, five layers for R2, and eight layers for R3, respectively. The ratios of cathode surface area/ anode spatial volume were $1,2.5$, and $4 \mathrm{~cm}^{2} / \mathrm{cm}^{3}$, respectively. The distance between the anode and cathode was fixed at $3 \mathrm{~cm}$. The liquid in the MEC reactor was mixed by magnetic stirring (400 rpm). External voltage was supplied by a switching power source (FDPS-150, Fudan Tianxin, Inc., China).

2.2. Startup and Operation of Semi-continuous MECs. MEC reactors were initially inoculated with excess activated sludge (Taiping sewage treatment plant, Harbin, China) and fed with culture solution, which consisted of $2000 \mathrm{mg} / \mathrm{L}$ sodium acetate, $50 \mathrm{mM}$ phosphate buffer solution (PBS; $4.09 \mathrm{~g} / \mathrm{L} \mathrm{Na}_{2} \mathrm{HPO}_{4}, 2.54 \mathrm{~g} / \mathrm{L} \mathrm{NaH}_{2} \mathrm{PO}_{4}, 0.31 \mathrm{~g} /$ $\mathrm{L} \mathrm{NH}_{4} \mathrm{Cl}$, and $0.13 \mathrm{~g} / \mathrm{L} \mathrm{KCl}$ ), and other additional trace elements according to the literature. ${ }^{3}$ During the startup stage, a constant voltage of $0.8 \mathrm{~V}$ was applied until the electrical potentials of anodes were below $-400 \mathrm{mV}{ }^{19}$ When all reactors were successfully started, the substrate was changed to artificial beer brewery wastewater, which consisted of diluted beer (Harbin beer), PBS, and trace elements, with the main characteristics as follows: COD, $1125 \pm 66 \mathrm{mg} / \mathrm{L} ; \mathrm{NH}_{3} \mathrm{~N}$, $28 \pm 5 \mathrm{mg} / \mathrm{L}$; and $\mathrm{pH}, 6.9 \pm 0.1$. Applied voltage varied from 0.5 to $0.9 \mathrm{~V}$. At least three batches ( $48 \mathrm{~h}$ for each batch) were repeated for each condition to obtain stable gas production. All reactors were kept in a thermostat incubator, and the temperature was maintained at $35 \pm$ $1{ }^{\circ} \mathrm{C}$.

2.3. Analytical and Calculation Methods. The voltage across the resistor $(10 \Omega)$ and electrode potential were measured using a multimeter/data acquisition system (model 2700, Keithley Instruments). Gas composition (methane, hydrogen, and carbon dioxide) was analyzed by a gas chromatograph (Agilent 7890, Santa Clara, CA, U.S.A.). COD, $\mathrm{pH}$, suspended solids, and ammonia $\left(\mathrm{NH}_{3} \mathrm{~N}\right)$ were analyzed according to the standard methods. ${ }^{20}$ The performance of MECs was evaluated by a series of efficiency indexes, including coulombic efficiency $\left(\eta_{\mathrm{CE}}\right)$, electrochemical contribution efficiency $\left(\eta_{\mathrm{ECE}}\right)$, overall electron-recovery efficiency $\left(\eta_{\mathrm{ER}}\right)$, and overall energy efficiency $\left(\eta_{\mathrm{EN}}\right)$, which are calculated according to refs 21 and 22 , and the calculation formulas were as follows:

Coulombic efficiency $\left(\eta_{\mathrm{CE}}\right)$ represented the ratio of electrons measured in electric current to the available electrons in the removed substrates and was calculated as the following equation:

$$
\eta_{\mathrm{CE}}=\frac{\int_{0}^{t} I \mathrm{~d} t}{\left(C_{t}-C_{0}\right) \frac{V}{M_{\mathrm{O}}} F b_{\mathrm{O}}} \times 100 \%
$$

Electrochemical contribution efficiency $\left(\eta_{\mathrm{ECE}}\right)$ was the percentage of methane that was produced with the electrons in the electric current, where it was supposed that all of the electrons in the electric current were captured in the target product, and calculation was conducted via the following equation:

$$
\eta_{\mathrm{ECE}}=\frac{\int_{0}^{t} I \mathrm{~d} t}{n_{\mathrm{CH}_{4}} \mathrm{Fb}_{\mathrm{CH}_{4}}} \times 100 \%
$$

The overall electron-recovery efficiency $\left(\eta_{\mathrm{ER}}\right)$ was the ratio of electrons that were transferred to the target product (methane) to the total electrons donated by the removed organic substrates, which was calculated as follows:

$$
\eta_{\mathrm{ER}}=\frac{\eta_{\mathrm{CH}_{4}}}{\eta_{\mathrm{CE}}} \times 100 \%
$$

The overall energy efficiency $\left(\eta_{\mathrm{EN}}\right)$ is the ratio between energy obtained via methane to the input energy provided by external power sources, which was calculated as follows:

$$
\eta_{\mathrm{EN}}=\frac{\Delta \mathrm{CH}_{4} n_{\mathrm{CH}_{4}}}{\left(\int_{0}^{t} I \mathrm{~d} t\right) E_{\mathrm{ap}}} \times 100 \%
$$

where $C_{t}$ and $C_{0}$ were the COD concentrations $(\mathrm{g} / \mathrm{L})$ of the substrate at the end and start of one batch, respectively, $V$ was the volume of liquid in each reactor (L), $F$ was the Faraday constant $(96485 \mathrm{C} / \mathrm{mol}$ of $\left.\mathrm{e}^{-}\right), M_{\mathrm{O}}$ was the molar weight of oxygen $(32 \mathrm{~g} / \mathrm{mol}), I$ was the current $(\mathrm{A}), b_{\mathrm{O}}$ was the moles of electrons transferred from the organic matter oxidized by $1 \mathrm{~mol}$ of oxygen ( $4 \mathrm{~mol}$ of $\mathrm{e}^{-} / \mathrm{mol}$ of oxygen), $t$ was the time of one batch (s), $n_{\mathrm{CH}_{4}}$ was the moles of methane produced (mol), $b_{\mathrm{CH}_{4}}$ was the moles of electrons obtained from oxidization per mole of methane ( $8 \mathrm{~mol}$ of $\mathrm{e}^{-} / \mathrm{mol}$ of methane), $\Delta \mathrm{CH}_{4}$ was the combustion heat value per mole of methane $(890300 \mathrm{~J} / \mathrm{mol}$ of methane), and $E_{\text {ap }}$ was the applied voltage $(\mathrm{V})$.

2.4. EBA. The EBA of three reactors at the end of the second batch in the stage of $0.9 \mathrm{~V}$ was performed. The total electrons donated by initial substrates were categorized into three parts: effluent COD, 
methane, and others (biomass). Electron flow to each part was calculated as follows:

effluent

$$
P_{\text {effluent }}=\frac{C_{t}}{C_{0}} \times 100 \%
$$

methane

$$
P_{\text {methane }}=\frac{n_{\mathrm{CH}_{4}} b_{\mathrm{CH}_{4}}}{C_{0} \frac{V}{M_{\mathrm{O}}} b_{\mathrm{O}}} \times 100
$$

The electrons accepted by methane were transferred via two approaches in the system. One is through the electrochemical reaction from cathodes to methanogens, including direct electron reduction of $\mathrm{CO}_{2}$ and indirect transfer of recovered hydrogen. ${ }^{8,23}$ This part was noted as electrochemical contribution and was calculated as follows:

$$
P_{\text {electrochemical }}=\frac{\int_{0}^{t} I \mathrm{~d} t}{C_{0} \frac{V}{M_{\mathrm{O}}} F b_{\mathrm{O}}} \times 100 \%
$$

The other approach was by intracellular conversion of acetoclastic methanogens, which accepted electrons directly from the substrates. It was supposed to be the remaining part of total methane deducting the electrochemical contribution, which was noted as the sole microbial contribution and calculated as follows:

$$
P_{\text {microbial }}=P_{\text {methane }}-P_{\text {electrochemical }}
$$

The remaining proportion of electrons, except those in the effluent and methane, was noted as others, which included the electrons absorbed by microbial organisms for growth and any other losses in the process of electron transfer, and it was calculated as follows:

$$
P_{\text {others }}=100 \%-P_{\text {effluent }}-P_{\text {methane }}
$$

\section{RESULTS AND DISCUSSION}

3.1. Effect of the Cathode/Anode Ratio on COD Removal and Methane Recovery. Effective removal of organic carbon and maximum recovery of methane were the main objectives for methane-producing MECs, and these two aspects were found to be improved in varying degrees by increasing cathode/anode ratios in this study. With artificial brewery wastewater severed as the substrate, all reactors with a stacked cathode showed considerable COD removals (65$80 \%)$. Increasing the cathode/anode ratio had no substantial effect on organic degradation (Figure 2A), indicating that cathodic biomass would dominantly function on electron recovery to biogas rather than substrate utilization. The COD removal in R3, which possessed the largest cathode/anode ratio, was only $8.1-8.5 \%$ higher than those in $\mathrm{R} 1$ and $\mathrm{R} 2$ under the highest applied voltage of $0.9 \mathrm{~V}$, and the differences in COD removal were even less than that with lower applied voltage. The COD removal indicated that primary contribution of electrons from substrate to MEC was mainly determined by the anode.

However, different from COD removal, the methane production rate and methane recovery were obviously influenced by the cathode/anode ratio (Figure $2 \mathrm{~B}$ ). When the ratio increased from $1 \mathrm{~cm}^{2} / \mathrm{cm}^{3}$ (R1) to $4 \mathrm{~cm}^{2} / \mathrm{cm}^{3}$ (R3) under $0.5 \mathrm{~V}$ voltage, the methane production rate increased by $20.8 \%$, from 0.048 to $0.058 \mathrm{~m}^{3} \mathrm{~m}^{-3} \mathrm{day}^{-1}$. The effect of the cathode/anode ratio played an important role when applied voltages increased. The methane production rate of $\mathrm{R} 3$ was greatly increased to $0.14 \mathrm{~m}^{3} \mathrm{~m}^{-3}$ day $^{-1}$ when the applied
A)

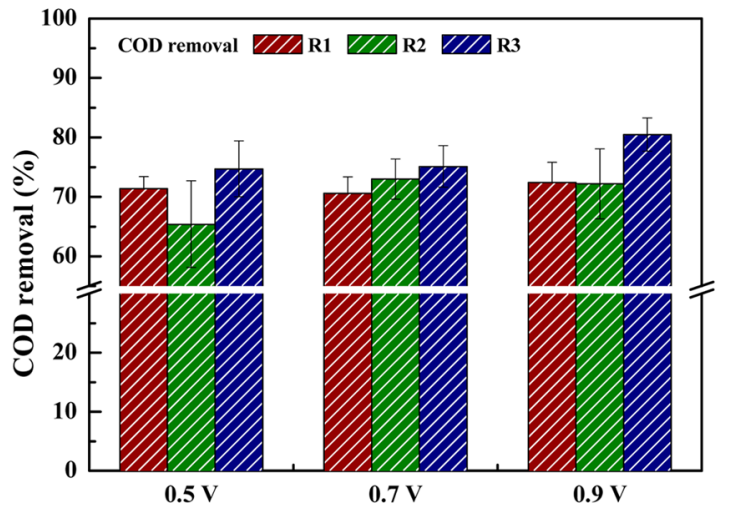

B)

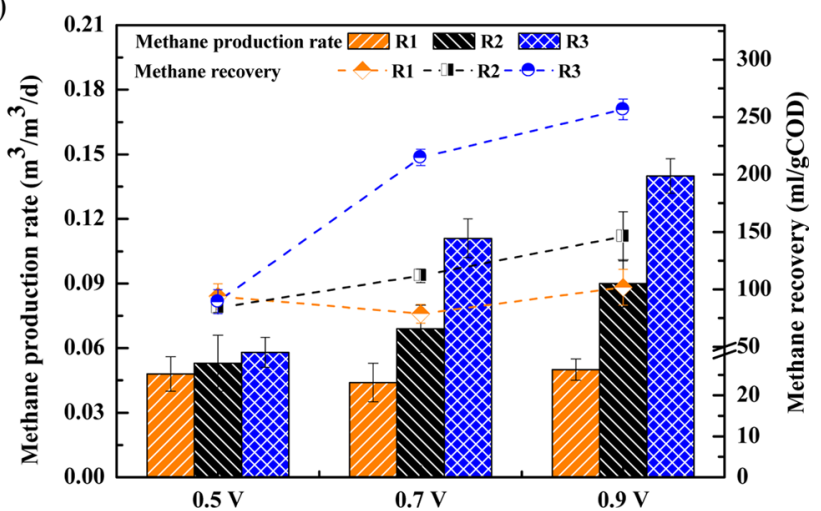

Figure 2. Performance of stacked cathode MECs with different cathode areas in (A) COD removal and (B) methane production.

voltage was $0.9 \mathrm{~V}$, which increased by 1.8 -fold compared to R1. The variation trend of methane recovery, calculated as the volume of methane recovered from per gram of COD in removed substrate, was consistent with the methane production rate (Figure 2). The methane recovery of all reactors achieved 84.1-93.9 $\mathrm{mL} / \mathrm{g}$ COD at the applied voltage of $0.5 \mathrm{~V}$. When the voltage was promoted to $0.9 \mathrm{~V}$, the methane recovery of R3 was significantly increased to $256.7 \mathrm{~mL} / \mathrm{g}$ COD, which was 1.5 fold higher than that of R1.

Substrate utilization mainly taook place on anodes as a result of the metabolism of anode microorganisms. ${ }^{24}$ Methanogenesis via electron transfer from electrode to methanogens was in the charge of the cathode. ${ }^{3}$ In this work, the variation of both the applied voltage and cathode area had slight influences on the substrate removal but strong influence on methane production, which indicated that the electron recovery process on the cathode (i.e., methanogensis) was probably the rate-limiting step in the system rather than the organic oxidation and electron transport processes on the anode. The cathode reactions of methane production have been assumed directly through $8 \mathrm{H}^{+}+8 \mathrm{e}+\mathrm{CO}_{2}=\mathrm{CH}_{4}+2 \mathrm{H}_{2} \mathrm{O}^{23}$ or indirectly through $2 \mathrm{H}^{+}+2 \mathrm{e}=\mathrm{H}_{2}$ and $4 \mathrm{H}_{2}+\mathrm{CO}_{2}=\mathrm{CH}_{4}+2 \mathrm{H}_{2} \mathrm{O}^{3}$. It has been detected that an increase of $\mathrm{pH}$ around the cathode when the above cathode reaction occurred ${ }^{19}$ indicated the limiting step determined by the cathode. Therefore, applying a stacked cathode with a high cathode area was a potential method to break through the restriction. In addition, the effect of increasing the cathode/anode ratio was more significant under higher voltages, inferring that the energy yield loss of overpotential at a high applied voltage can be reduced by applying a high cathode/anode ratio. ${ }^{25}$ 
Table 1. Electrochemical Efficiency of Each Reactor

\begin{tabular}{|c|c|c|c|c|}
\hline electrochemical efficiency & applied voltage $(\mathrm{V})$ & $\mathrm{R} 1\left(1 \mathrm{~cm}^{2} / \mathrm{cm}^{3}\right)$ & $\mathrm{R} 2\left(2.5 \mathrm{~cm}^{2} / \mathrm{cm}^{3}\right)$ & $\mathrm{R} 3\left(4 \mathrm{~cm}^{2} / \mathrm{cm}^{3}\right)$ \\
\hline \multirow[t]{3}{*}{ average current, $I(\mathrm{~mA})$} & 0.5 & $1.9 \pm 0.1$ & $3.1 \pm 0.1$ & $3.3 \pm 0.2$ \\
\hline & 0.7 & $4.7 \pm 0.1$ & $7.6 \pm 0.2$ & $8.0 \pm 0.1$ \\
\hline & 0.9 & $8.4 \pm 0.2$ & $12.9 \pm 0.3$ & $12.6 \pm 0.1$ \\
\hline \multirow[t]{3}{*}{ anode coulombic efficiency, $\eta_{\mathrm{CE}}(\%)$} & 0.5 & $5.0 \pm 0.3$ & $9.5 \pm 2.2$ & $8.1 \pm 3.0$ \\
\hline & 0.7 & $12.1 \pm 1.2$ & $19.2 \pm 3.1$ & $19.5 \pm 3.4$ \\
\hline & 0.9 & $21.2 \pm 2.1$ & $32.7 \pm 3.5$ & $28.6 \pm 5.7$ \\
\hline \multirow[t]{3}{*}{ electrochemical contribution efficiency, $\eta_{\mathrm{ECE}}(\%)$} & 0.5 & $14.6 \pm 1.4$ & $21.1 \pm 1.9$ & $20.4 \pm 2.3$ \\
\hline & 0.7 & $37.9 \pm 3.1$ & $39.5 \pm 3.2$ & $25.8 \pm 3.5$ \\
\hline & 0.9 & $60.9 \pm 6.2$ & $52.1 \pm 4.3$ & $31.3 \pm 3.1$ \\
\hline \multirow[t]{3}{*}{ overall electron-recovery efficiency, $\eta_{\mathrm{ER}}(\%)$} & 0.5 & $34.1 \pm 5.4$ & $45.2 \pm 3.7$ & $39.8 \pm 3.2$ \\
\hline & 0.7 & $32.1 \pm 3.9$ & $48.5 \pm 3.5$ & $75.5 \pm 5.7$ \\
\hline & 0.9 & $34.8 \pm 6.1$ & $62.6 \pm 4.8$ & $91.2 \pm 6.0$ \\
\hline \multirow[t]{3}{*}{ overall energy-recovery efficiency, $\eta_{\mathrm{EN}}(\%)$} & 0.5 & $1583.6 \pm 113.2$ & $1094.4 \pm 60.5$ & $1128.7 \pm 51.7$ \\
\hline & 0.7 & $610.4 \pm 91.7$ & $584.3 \pm 22.3$ & $894.0 \pm 40.5$ \\
\hline & 0.9 & $378.9 \pm 54.8$ & $442.0 \pm 21.2$ & $735.1 \pm 32.5$ \\
\hline \multirow[t]{3}{*}{ cathodic current density, $i_{\mathrm{C}}\left(\mathrm{mA} / \mathrm{m}^{2}\right)$} & 0.5 & $251.2 \pm 11.8$ & $162.3 \pm 4.6$ & $113.2 \pm 6.0$ \\
\hline & 0.7 & $600.3 \pm 12.5$ & $394.1 \pm 10.3$ & $262.7 \pm 3.3$ \\
\hline & 0.9 & $1082.1 \pm 25.4$ & $663.5 \pm 14.8$ & $415.3 \pm 5.0$ \\
\hline
\end{tabular}

3.2. Effect of the Cathode/Anode Ratio on the Current and Energy Recovery. The current is an important electrochemical performance indicator of MECs and characterized the ability of electron recovery and transfer through biological electrochemical action in MEC. In this study, the cathode/anode ratio was introduced to regulate the ability of electron generation in the bioanode and electron recovery in the biocathode. The currents in R2 and R3 both increased to a maximal level, which were obviously higher than that in R1 at all stages, indicating that the cathode reaction was a limited factor when the cathode/anode ratio was insufficient (Table 1). For example, the currents in R2 and R3 at an applied voltage of $0.9 \mathrm{~V}$ were 12.9 and $12.6 \mathrm{~mA}$, respectively, while in $\mathrm{R} 1$, it was $8.4 \mathrm{~mA}$. It instructed that the bioelectrolysis process was limited by the insufficient cathode area when the cathode/anode ratio was less than $2.5 \mathrm{~cm}^{2} / \mathrm{cm}^{3}$. The current was not further increased when the cathode/anode ratio was above $2.5 \mathrm{~cm}^{2}$ / $\mathrm{cm}^{3}$, indicating that the cathode area was not the limiting factor for improving bioelectrochemical performance any more.

The cathodic current density in MECs significantly decreased with the enlargement of the cathode/anode ratio (Table 1), which was $1082.1 \mathrm{~mA} / \mathrm{m}^{2}$ in $\mathrm{R} 1$ and decreased to $663.5 \mathrm{~mA} / \mathrm{m}^{2}$ in R2 at the voltage of $0.9 \mathrm{~V}$. It further decreased to $415.3 \mathrm{~mA} /$ $\mathrm{m}^{2}$ in R3. On the basis of electrochemistry principles, the overpotential of the reduction reaction that happened on the cathode (cathodic activation overpotential) has a positive correlation with the current density. ${ }^{26,27}$ Therefore, applying a high-surface-area cathode would cause a decrease of the overpotential through a reduction of the current density and, ultimately, result in an enhancement of cathodic efficiency.

The overall electron-recovery efficiency and overall-energy efficiency were also significantly promoted by increasing the cathode/anode ratio (Table 1 ). The overall electron recovery in R3 was $91.2 \%$ at the voltage of $0.9 \mathrm{~V}$, which was $28.6 \%$ higher than that in R2 (62.6\%) and 56.4\% higher than that in R1 (34.8\%). That indicated that more electrons transferred into in the target product (methane) in MECs with a larger cathode/ anode ratio. The overall energy-recovery efficiency was $735.1 \%$ in R3 at the voltage of $0.9 \mathrm{~V}$, which was $293.1 \%$ higher than that in R2 and $356.2 \%$ higher than that in R1. Apparently, energy recovery from organic substrates was benefited by increasing the cathode area. It has been pointed out that the capital cost was an important issue for the development of bioelectrochemical systems and technologies. ${ }^{28}$ Considering the perspectives of operating costs and interests, maximizing the cathode/anode ratio was a feasible strategy to optimize methane production in MEC configuration design.

3.3. Evaluation of Methane Conversion Based on EBA. The results of EBA revealed the contributions of the bioelectrochemical reaction and sole microbial metabolism to the methane production in MECs. Under the voltage of $0.9 \mathrm{~V}$, electrochemical contribution increased from 15 to $24 \%$ when the cathode/anode ratio increased twice from R1 to R2 (Figure 3A). Nevertheless, further increasing the cathode/anode ratio achieved a similar electron contribution as a result of the similar current in R2 and R3. Unlike electrochemical contribution, the sole microbial contribution to methane production kept rising with the increase of the cathode/anode ratio. The microbial contribution to methane in $\mathrm{R} 3$ ( $47.6 \%$ of total electrons) was much higher than that in R2 (16.4\%), which explained the different methane productions between R2 and R3. Moreover, a significant decrease of the electron percentage in the effluent and the rest of the part illustrated that increasing the cathode/ anode ratio could reduce the energy loss and improve wastewater treatment efficiency and overall energy conversion.

To verify the results of EBA and have a clear idea about the abilities of MECs in producing methane without an applied voltage, R1, R2, and R3 were operated under an open-circuit condition (with no applied voltage) for three batches. The results showed that methane productions in a single batch under an open-circuit condition increased with the enlargement of the cathode/anode ratio, and they were very close to the values of microbial-contributed methane under a closed-circuit condition calculated by EBA in R2 and R3, which provided solid proof to support the results of EBA. As for the significant difference between experimental data and the calculated value in R1, it was probably because of the low biomass of methanogens in $\mathrm{R} 1$ as a result of the insufficient cathode area. Methanogens were able to obtain substrates from both the electrochemical process and anaerobic digestion process, when methanogen biomass was the limiting factor of methanogensis (such as R1), and the substrates provided by the anaerobic 
A)

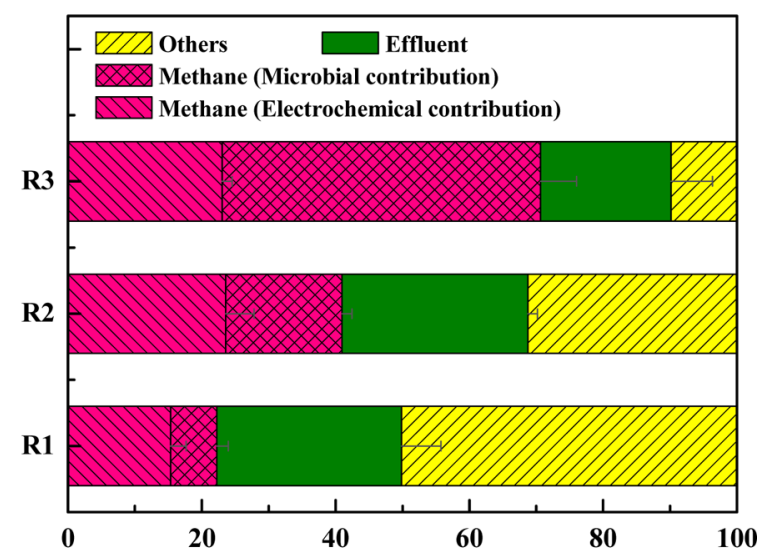

B)

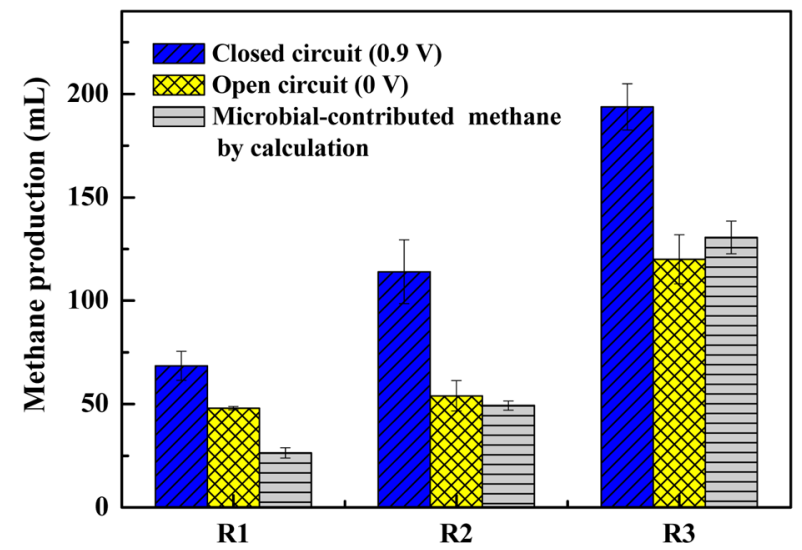

Figure 3. (A) EBA of stacked cathode MEC with different cathode areas under the applied voltage of $0.9 \mathrm{~V}$ and (B) methane production under a closed-circuit condition and an open-circuit condition and calculated microbial-contributed methane under a closed-circuit condition.

digestion process might not been fully used under a closedcircuit condition but would be exhausted when the applied voltage was cut off.

It has been proven that electrodes could provide niches for methanogens in MEC systems, ${ }^{9}$ but the colonization of methanogens on the anode generally had a negative effect on the bioelectrolysis performance of MEC because of the competition between methanogens and exoelectrogens. ${ }^{3}$ Different from the case of the anode, the increased biomass retention on the cathode as a result of the increase of the cathode surface area maintained a stable bioelectrochemical conversion to biogas and substantially promoted the overall methane yield.

\section{CONCLUSION}

Efficient methane production was achieved in membraneless MECs with stacked cathodes. Increasing the cathode/anode ratio significantly improved the bioelectrochemical methane production and promoted the overall energy recovery from organic wastewater. The cathode area was sufficient for obtaining and maintaining a maximum current when the cathode/anode ratio was higher than $2.5 \mathrm{~cm}^{2} / \mathrm{cm}^{3}$. In addition to the enhancement of the electrochemical performance, increasing biomass retention from a large cathode surface area also notably contributed to the methane recovery by improving system stability and decreasing energy lost in the effluent.

\section{AUTHOR INFORMATION}

\section{Corresponding Authors}

*E-mail: waj0578@hit.edu.cn.

*E-mail: wzliu@rcees.ac.cn.

ORCID ${ }^{\circ}$

Aijie Wang: 0000-0002-4398-5300

Notes

The authors declare no competing financial interest.

\section{ACKNOWLEDGMENTS}

This research was supported by the National Natural Science Foundation of China (51578534), the "Hundred Talents Program" of the Chinese Academy of Sciences, and Youth Innovation Promotion Association CAS.

\section{REFERENCES}

(1) Du, Z.; Li, H.; Gu, T. A state of the art review on microbial fuel cells: A promising technology for wastewater treatment and bioenergy. Biotechnol. Adv. 2007, 25 (5), 464-482.

(2) Zhang, Y.; Angelidaki, I. Microbial electrolysis cells turning to be versatile technology: Recent advances and future challenges. Water Res. 2014, 56, 11-25.

(3) Wang, A.; Liu, W.; Cheng, S.; Xing, D.; Zhou, J.; Logan, B. E. Source of methane and methods to control its formation in single chamber microbial electrolysis cells. Int. J. Hydrogen Energy 2009, 34 (9), 3653-3658.

(4) Villano, M.; Scardala, S.; Aulenta, F.; Majone, M. Carbon and nitrogen removal and enhanced methane production in a microbial electrolysis cell. Bioresour. Technol. 2013, 130, 366-371.

(5) Zhen, G.; Lu, X.; Kobayashi, T.; Kumar, G.; Xu, K. Promoted electromethanosynthesis in a two-chamber microbial electrolysis cells (MECs) containing a hybrid biocathode covered with graphite felt (GF). Chem. Eng. J. 2016, 284, 1146-1155.

(6) Villano, M.; Aulenta, F.; Ciucci, C.; Ferri, T.; Giuliano, A.; Majone, M. Bioelectrochemical reduction of $\mathrm{CO}(2)$ to $\mathrm{CH}(4)$ via direct and indirect extracellular electron transfer by a hydrogenophilic methanogenic culture. Bioresour. Technol. 2010, 101 (9), 3085-3090.

(7) Sangeetha, T.; Guo, Z.; Liu, W.; Cui, M.; Yang, C.; Wang, L.; Wang, A. Cathode material as an influencing factor on beer wastewater treatment and methane production in a novel integrated upflow microbial electrolysis cell (Upflow-MEC). Int. J. Hydrogen Energy 2016, 41 (4), 2189-2196.

(8) Liu, W.; Cai, W.; Guo, Z.; Wang, L.; Yang, C.; Varrone, C.; Wang, A. Microbial electrolysis contribution to anaerobic digestion of waste activated sludge, leading to accelerated methane production. Renewable Energy 2016, 91, 334-339.

(9) De Vrieze, J.; Gildemyn, S.; Arends, J. B.; Vanwonterghem, I.; Verbeken, K.; Boon, N.; Verstraete, W.; Tyson, G. W.; Hennebel, T.; Rabaey, K. Biomass retention on electrodes rather than electrical current enhances stability in anaerobic digestion. Water Res. 2014, 54, 211-221.

(10) Logan, B. E.; Wallack, M. J.; Kim, K.-Y.; He, W.; Feng, Y.; Saikaly, P. E. Assessment of Microbial Fuel Cell Configurations and Power Densities. Environ. Sci. Technol. Lett. 2015, 2 (8), 206-214.

(11) Alatraktchi, F. A.; Zhang, Y.; Noori, J. S.; Angelidaki, I. Surface area expansion of electrodes with grass-like nanostructures and gold nanoparticles to enhance electricity generation in microbial fuel cells. Bioresour. Technol. 2012, 123, 177-183.

(12) Alatraktchi, F. A. a.; Zhang, Y.; Angelidaki, I. Nanomodification of the electrodes in microbial fuel cell: Impact of nanoparticle density on electricity production and microbial community. Appl. Energy 2014, 116, 216-222.

(13) Hou, Y.; Zhang, R.; Luo, H.; Liu, G.; Kim, Y.; Yu, S.; Zeng, J. Microbial electrolysis cell with spiral wound electrode for wastewater treatment and methane production. Process Biochem. 2015, 50 (7), 1103-1109. 
(14) Jia, B.; Hu, D.; Xie, B.; Dong, K.; Liu, H. Increased power density from a spiral wound microbial fuel cell. Biosens. Bioelectron. 2013, 41, 894-897.

(15) Wang, H.; Zhang, Y.; Angelidaki, I. Ammonia inhibition on hydrogen enriched anaerobic digestion of manure under mesophilic and thermophilic conditions. Water Res. 2016, 105, 314-319.

(16) Zhang, Y.; Angelidaki, I. Counteracting ammonia inhibition during anaerobic digestion by recovery using submersible microbial desalination cell. Biotechnol. Bioeng. 2015, 112 (7), 1478-1482.

(17) Zhang, Y.; Angelidaki, I. Recovery of ammonia and sulfate from waste streams and bioenergy production via bipolar bioelectrodialysis. Water Res. 2015, 85, 177-184.

(18) Parameswaran, P.; Torres, C. I.; Lee, H. S.; Krajmalnik-Brown, R.; Rittmann, B. E. Syntrophic Interactions Among Anode Respiring Bacteria (ARB) and Non-ARB in a Biofilm Anode: Electron Balances. Biotechnol. Bioeng. 2009, 103 (3), 513-523.

(19) Wang, A.; Liu, W.; Ren, N.; Zhou, J.; Cheng, S. Key factors affecting microbial anode potential in a microbial electrolysis cell for H2 production. Int. J. Hydrogen Energy 2010, 35 (24), 13481-13487.

(20) Guo, Z.; Zhou, A.; Yang, C.; Liang, B.; Sangeetha, T.; He, Z.; Wang, L.; Cai, W.; Wang, A.; Liu, W. Enhanced short chain fatty acids production from waste activated sludge conditioning with typical agricultural residues: Carbon source composition regulates community functions. Biotechnol. Biofuels 2015, 8 (1), 1-14.

(21) Cai, W.; Han, T.; Guo, Z.; Varrone, C.; Wang, A.; Liu, W. Methane production enhancement by an independent cathode in integrated anaerobic reactor with microbial electrolysis. Bioresour. Technol. 2016, 208, 13-18.

(22) Cui, M. H.; Cui, D.; Lee, H. S.; Liang, B.; Wang, A. J.; Cheng, H. Y. Effect of electrode position on azo dye removal in an up-flow hybrid anaerobic digestion reactor with built-in bioelectrochemical system. Sci. Rep. 2016, 6, 25223.

(23) Cheng, S.; Xing, D.; Call, D. F.; Logan, B. E. Direct Biological Conversion of Electrical Current into Methane by Electromethanogenesis. Environ. Sci. Technol. 2009, 43 (10), 3953-3958.

(24) Liu, W.; Wang, A.; Cheng, S.; Logan, B. E.; Yu, H.; Deng, Y.; Nostrand, J. D. V.; Wu, L.; He, Z.; Zhou, J. Geochip-Based Functional Gene Analysis of Anodophilic Communities in Microbial Electrolysis Cells under Different Operational Modes. Environ. Sci. Technol. 2010, 44 (19), 7729-7735.

(25) Selembo, P. A.; Merrill, M. D.; Logan, B. E. Hydrogen production with nickel powder cathode catalysts in microbial electrolysis cells. Int. J. Hydrogen Energy 2010, 35 (2), 428-437.

(26) Freguia, S.; Rabaey, K.; Yuan, Z.; Keller, J. Non-catalyzed cathodic oxygen reduction at graphite granules in microbial fuel cells. Electrochim. Acta 2007, 53 (2), 598-603.

(27) Pinto, R. P.; Srinivasan, B.; Escapa, A.; Tartakovsky, B. Multipopulation model of a microbial electrolysis cell. Environ. Sci. Technol. 2011, 45 (11), 5039-5046.

(28) Zhang, Y.; Angelidaki, I. Microbial Electrochemical Systems and Technologies: It Is Time To Report the Capital Costs. Environ. Sci. Technol. 2016, 50 (11), 5432-5433. 